\title{
Population viability of captive Asian elephants in the Lao PDR
}

\author{
Ingrid Colette Suter ${ }^{1, *}$, Gilles Pierre Maurer ${ }^{2}$, Greg Baxter ${ }^{1}$ \\ ${ }^{1}$ The University of Queensland, School of Geography, Planning and Environmental Management, St Lucia, Brisbane, \\ Queensland 4072, Australia \\ ${ }^{2}$ ElefantAsia, PO Box 3804, Vientiane, Lao People's Democratic Republic
}

\begin{abstract}
Asian elephants Elephas maximus have been captured and trained by Lao mahouts for centuries. While captive elephants are losing their traditional relevance, they still play a significant role in the Lao logging and tourism industries. However, with only an estimated 480 captive elephants remaining nationally and only $\sim 60$ cows under $35 \mathrm{yr}$ of age, the future viability of this population is uncertain. We assessed $>80 \%$ of the captive elephant population and used VORTEX software to create 7 population viability analysis scenarios. Our results demonstrate that without changes to conservation management the current population is likely to be extinct in $112 \mathrm{yr}(\mathrm{r}=$ -0.099). Reduced mortality rates, increased reproductive rates and population supplementation will give the population an additional $108 \mathrm{yr}$ of longevity, but will not, of themselves, prevent extinction. Management programs should direct efforts towards in situ breeding programs, a cessation in calf exportation, improved veterinary care and population supplementation. Since captive populations are also small and declining in other range nations, there is also a case for managing all Asian elephants as a single management unit.
\end{abstract}

KEY WORDS: Asian elephants · Captive elephants · Elephas maximus $\cdot$ Lao PDR $\cdot$ Population viability · VORTEX

\section{INTRODUCTION}

Asian elephant Elephas maximus populations are in global decline. Total E. maximus numbers have been reduced by at least $50 \%$ in all 13 range nations in the last 3 generations (Bandara \& Tisdell 2004, Hedges et al. 2005, Choudhury et al. 2008) and the species is classified as Endangered by the IUCN (Choudhury et al. 2008). Total population estimates vary between 30000 and 50000 , although this is widely believed to be an outdated overestimate (Sukumar 2003, Hedges et al. 2005, Dublin et al. 2006, Hedges 2006, Choudhury et al. 2008). What research has been undertaken has focused mainly on wild elephants and not the sizeable captive population (Lair 1997, Hedges et al. 2005, Hedges 2006, Sukumar 2006). The captive elephant population constitutes one-third to one-quarter of all remaining Asian elephants (Sukumar 2003, Leimgruber et al. 2008). An estimated 14500 to 16000 elephants live in captive or semi-wild conditions, typically used for logging, village, tourism, or temple purposes (Sukumar 2003, Dublin et al. 2006). While the captive population is a significant percentage of total elephant numbers, these numbers are also declining (Khounboline 2011).

The Lao People's Democratic Republic (PDR) contains Indochina's largest remaining Asian elephant population (Ahlering et al. 2011). Even so, only an estimated 600 to 800 wild and 500 captive elephants remain throughout Laos, with both wild and captive populations in decline (Khounboline 2011, Ministry of Agriculture and Forestry 2009). Major threats to wild elephant populations include habitat loss and 
fragmentation, poaching and human-elephant conflict (Norachack 2002, Sukumar 2006, Khounboline 2011). A lack of capacity and investment in conservation are also recognized as major species management impediments (Norachack 2002, Ministry of Agriculture and Forestry 2009).

For centuries captive elephants have shaped Lao communities, with only minor deviations from traditional practices occurring. Both elephant acquisition and usage have changed, bringing about a major change in mahout lifestyle. Historically a calf would be captured from the wild as needed by the local mahout community. The viability of the captive elephant population was never considered until the Government of Laos introduced a ban on wild elephant capture in 1989 (Sukumar 2003). This ban had an immediate impact on the captive elephant population, with few calves entering the population since 1989 (Fig. 1). As long as elephants were traditionally captured from wild populations, mahouts never needed any knowledge of elephant reproduction (Lair 1997). As a result, the captive population now confronts a number of demographic challenges such as an aging population, inadequate replacement rate, a declining number of females of reproductive age, a lack of breeding opportunities and, recently, excessive calf exportation (Lair 1997, Sukumar 2003, ElefantAsia 2007, Khounboline 2011). Under CITES rental agreements it is believed that over the past 5 yr the Government of Laos has exported an estimated $10 \%$ of the nation's calves (S. Duffillot, pers. comm., 12 September 2012). Rentals or outright gifts are typically granted to countries sympathetic to Laos' political agenda, including China, North Korea

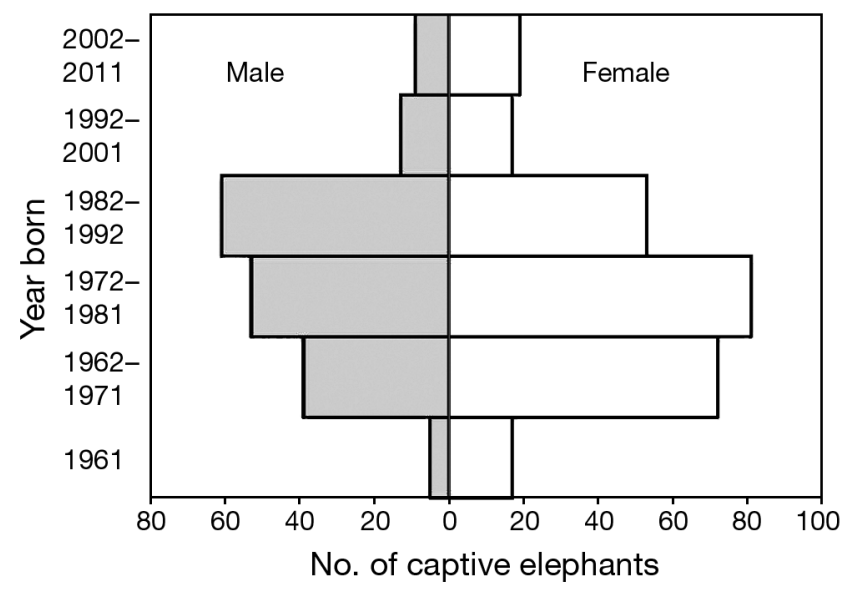

Fig. 1. Elephas maximus. Sex and age pyramid of the Lao captive elephant population $(\mathrm{n}=439)$. The majority of elephants were captured from the wild as calves before the 1989 ban on wild elephant capture and Japan (Suter 2012). The consequence of these demographic challenges has led to an extremely low captive breeding rate. In 2011, only 18 captive calves under the age of $10 \mathrm{yr}$ were documented in Laos (Xaymountry \& Maurer 2011).

Still offering much-needed employment for Lao mahouts and communities, captive elephant industries are undergoing significant change. Traditionally utilized for transportation and small-scale village use, the majority of captive elephants in Laos are now employed in the professional logging or tourism industries (Suter et al. 2013). Similar to Thailand, in less than $30 \mathrm{yr}$, elephant-based tourism has become a principal component of the national tourism industry (Kontogeorgopoulos 2009). The use of captive elephants for tourism purposes has been recognized as holding great significance for the long-term conservation of both wild and captive elephant populations (Duffy \& Moore 2011). While still in a nascent state, the Laos tourism industry has become one of the most important sources of foreign exchange and employment, and a major contributor to the national economy (Phakdisoth \& Kim 2007, Harrison \& Schipani 2009). Lao mahouts perceive tourism to be an easier lifestyle, offering lower pay but greater job security than the diminishing logging industry (Suter et al. 2013). Certainly within Laos, mahouts are willing to switch to tourism once logging in their region becomes unviable (Suter et al. 2013). The Lao elephant-based tourism industry endeavors to provide mahouts, and the national economy, with long-term benefits, as well as being an industry compatible with elephant reproductive needs.

More demographic data are available for the captive elephant population in Laos than for the wild population. Wild population numbers remain estimates, with threatening processes largely uncontrolled. Captive elephants have been registered and monitored by the Department of Livestock and Fisheries (DLF) and conservation groups, with sex, age, location and ownership details of $>80 \%$ of the entire captive elephant population recorded (ElefantAsia 2012). This knowledge makes it easier to develop management programmes for captive elephants than for their wild counterparts.

Given the significance of the captive elephant population in Laos, their decline would be detrimental to captive elephant populations, mahouts, businesses and local communities. To understand the reasons for, and the trajectory of, the declining captive elephant population we addressed the following questions: 
(1) What is the long-term viability of Lao captive elephants under current management regimes?

(2) Can conservation strategies prevent the localized extinction of elephants?

\section{MATERIALS AND METHODS}

\section{Study area}

Our study area encompassed all districts and provinces in the Lao PDR that had captive elephants microchipped and registered with the DLF and ElefantAsia between January 2009 and January 2012. This included the Bokeo, Bolikhamxai, Champassak, Luang Prabang, Oudomxay, Saravane, Sayaboury and Vientiane provinces (ElefantAsia 2012). Once microchipped, unique identification and demographic data were entered into the Lao national elephant registration database, which we utilized for this study.

\section{Modelling}

To assess the likelihood of Lao captive elephant extinction we carried out population viability analysis (PVA) using VORTEX Version 9.5. PVA is commonly used by researchers involved in captive breeding groups and by conservation managers to gauge minimal population viability or extinction rates for populations at risk (Lacy 1993, Beissinger \& Westphal 1998). PVA modeling is typically integrated into conservation planning, as programs accept assumptive parameters and environmental variation, and allow for adaptive species management (Akçakaya \& Sjögren-Gulve 2000, Lacy 2000, Myroniuk 2004). VORTEX software was chosen for our analyses as its simulation program is suitable for species with low fecundity, long life spans and uneven sex ratios (Lacy 1993, Miller \& Lacy 2005). Asian elephant PVA has been undertaken on wild populations in Sumatra (Sukumar \& Santiapillai 1993), wild populations in Sri Lanka (Sukumar 2003) and captive populations in Myanmar (Leimgruber et al. 2008). Perhaps because of the controllable environment in which they exist, and the substantial investments made by zoos, Asian elephant PVA has often been performed on small, ex situ populations rather than populations in home ranges. Ex situ Asian elephant PVA includes populations in Australian zoos (Myroniuk 2004), North American zoos (Faust et al. 2006) and the viability of Asian elephant cows in European zoos (Clubb et al. 2009).
Similar to Leimgruber et al. (2008) we ran our model on a $500 \mathrm{yr}$ timeframe rather than 100 or 1000 yr. A 100 yr timeframe may give declining populations false indicators of population perpetuity (Armbruster et al. 1999). Moderately longer timescales are recommended for populations with a negative growth rate and long generations. Given the Lao context we considered a 1000 yr timeframe as having too many unknown variables (political and environmental) to provide as meaningful an analysis as a 500 yr time scale. To test our baseline scenario rigour we ran sensitivity analyses against 2 vital parameters: percent of females breeding and calf mortality. Neither increases nor decreases of $20 \%$ affected the model.

\section{Baseline parameters for PVA scenarios}

Parameters for the 7 scenarios were determined from the Lao national elephant registration database and other published demographic data (Lair 1997, Leimgruber et al. 2008, ElefantAsia 2012) (Table 1). From the database we were able to accurately specify vital parameters, such as elephant age, sex and initial population size. The population was considered a single, closed population with no migration, rather than several small populations. We considered this to be realistic as mahouts routinely buy, sell, rent, or move elephants between provinces, as economic drivers demand. Migration was not included, as illegally exported calves will typically be unknown to ElefantAsia and not contained in the database. If the elephant was included in the database, its entry would be deactivated once exported and not incorporated in this analysis. Initial population size was 431, of which 253 were cows and 178 bulls (ElefantAsia 2012). This figure includes only calves and elephants of reproductive age. Maximum age of reproduction for cows and bulls was 55 yr (Mar 2002, Leimgruber et al. 2008). Carrying capacity was 517 - 20\% above the current population size.

Following Leimgruber et al. (2008), the age of first offspring and the mortality rates for bulls and cows were considered to be alike, since we did not wish to overstate the rate of extinction. We used infant mortality rates based on Leimgruber et al. (2008) for captive elephants rather than wild elephant mortality rates indicated by Armbruster et al. (1999) or wild elephant mortality rates for Sri Lankan populations (Sukumar 2003). This was considered appropriate as captive elephants face fewer environmental threats and have better veterinary care than wild calves. 
Similarly, we chose an even sex ratio at birth. While Lao mahouts believe slightly more males are conceived (authors' pers. obs.), male calves tend to have a higher perinatal and juvenile mortality rate (Saragusty et al. 2009). Juvenile bull behaviour and higher risk-taking typically lead to higher mortality rates in this sex (Sukumar 2003).

Percentage of breeding females was calculated by analyzing the past $4 \mathrm{yr}$ of captive elephant births recorded in the database (ElefantAsia 2012) (Table 2). This is the most accurate Lao captive elephant data ever recorded, and it was considered necessary to use actual representative values rather than breeding estimates from other elephant studies. The aver- age percentage of breeding females was low $(2.3 \%)$, but we considered this an accurate portrayal of the current Lao context. Percentage of males in the breeding pool was $80 \%$ (Leimgruber et al. 2008), as social hierarchy dictates that not all bulls have the opportunity to reproduce. However, as most calves are sired by wild bulls, the fertility of captive bulls remains unknown.

We did not include harvesting in any scenario, nor did we include any wild elephant population demographics in our scenarios. With wild elephant populations poorly monitored and managed, we focused solely on the population with known and controllable conservation management.
Table 1. Elephas maximus. Baseline parameters and 7 management scenarios applied in VORTEX for Lao captive elephant population viability analyses. Age applies to both sexes. All model scenarios were repeated 1000 times over $500 \mathrm{yr}$

\begin{tabular}{|ll|}
\hline Parameter & Description \\
\hline BASELINE & \\
Mating system & $\begin{array}{c}\text { Polygynous, } 80 \% \text { of males and } 2.3 \% \\
\text { females in breeding pool }\end{array}$ \\
Sexual maturity & $\begin{array}{c}15 \text { yr for both sexes, maximum } \\
\text { reproductive age } 55 \text { yr }\end{array}$ \\
Litter size & 1 with a 1:1 sex ratio at birth \\
Initial population structure & Specified aged distribution \\
Age (yr) & Mortality (\%) \\
$0-5$ & 8 \\
$5-15$ & 2.1 \\
$>15$ & 2.9 \\
Initial population size & 431 \\
Carrying capacity & 512 \\
MODEL ITERATIONS & \\
Scenario 1 & Current captive/baseline population \\
Scenario 2 & Scenario $1+5 \%$ higher fecundity \\
Scenario 3 & Scenario $1+10 \%$ higher fecundity \\
Scenario 4 & Scenario $2+50 \%$ lower mortality \\
Scenario 5 & Scenario $3+50 \%$ lower mortality \\
Scenario 6 & Scenario $5+5$ calves supplemented \\
Scenario 7 & Scenario $5+10$ calves supplemented \\
\hline
\end{tabular}

Table 2. Elephas maximus. Reproductive rate of captive cows in Laos from 2008 to 2011. New elephants were added to the database as they were microchipped

\begin{tabular}{|cccccc|}
\hline Year & $\begin{array}{c}\text { No. of } \\
\text { elephants }\end{array}$ & $\begin{array}{c}\text { No. of cows } \\
\text { 15-55 yr }\end{array}$ & $\begin{array}{c}\text { No. of } \\
\text { births }\end{array}$ & $\begin{array}{c}\text { \% of births } \\
\text { (population) }\end{array}$ & $\begin{array}{c}\text { Reproductive } \\
\text { rate }\end{array}$ \\
\hline 2008 & 432 & 229 & 5 & 1.16 & 2.2 \\
2009 & 434 & 231 & 3 & 0.69 & 1.3 \\
2010 & 440 & 232 & 7 & 1.59 & 3 \\
2011 & 439 & 226 & 6 & 1.37 & 2.7 \\
Total & & & 21 & 1.20 & 2.3 \\
\hline
\end{tabular}

\section{RESULTS}

All our simulations indicate that Laos' captive elephant population is not selfsustaining. The current captive population has a negative growth rate $(\mathrm{r}=-0.099)$ (Table 3). Mortality rates are higher than reproductive rates. Our baseline population shows the captive elephant population is likely to become extinct in $112 \mathrm{yr}$. In no scenario was the carrying capacity reached. Reducing mortality, increasing birth rates and population supplementation reduced the rate at which the population reached extinction, but did not stop it. Scenario 7 provided the Lao captive elephant population with the longest persistence, but even then our model predicted extinction within 220 yr (Fig. 2).

\section{DISCUSSION}

Current management regimes are not sufficient to support the long-term viability of the Lao captive elephant population. Our results are similar to those from studies of Myanmar captive elephant populations (Mar 2002, Leimgruber et al. 2008) and Thai elephants in Australian zoos (Myroniuk 2004). However, while the parameters used are largely representative of the Lao elephant population, mortality rates are estimates and not necessarily representative of the true mortality rate, particularly for calves. The $8 \%$ mortality rate for calves taken from Leimgruber et 
al. (2008) may be too high, producing an excessive extinction rate. Understanding the real mortality rates for this population will provide greater accuracy in further population viability analysis. Furthermore, increased funding for additional conservation management will permit a greater delivery of services. This will facilitate improved reproductive and veterinary efforts. We suggest conservation management aims to provide better outreach services to mahouts and their elephants, ensuring a regular birth and death census, as well as services to lower elephant mortality rates and increase fecundity rates, and the consideration of population supplementation.

\section{Reducing mortality rates}

Very little information is known about mortality rates and the official causes of death among captive Lao elephants. Deaths are often underreported by mahouts; post mortems are rarely performed, and there is minimal access to laboratories for blood and tissue analysis (Labatut \& Suter 2010). While the healthcare of captive elephants is improving, a lack of robust knowledge about disease and infection rates combined with a lack of national capacity to contain potential disease outbreaks should be recognized as major threats to captive elephants. A reduction in mortality rates should, therefore, focus on continued veterinary checks, mahout education, improving laboratory facilities and disease diagnosis, infectious disease assessments and more frequent post mortem analysis. Emerging diseases such as elephant endotheliotropic herpesvirus and tuberculosis represent addition threats to elephants. No studies have been performed to assess wild elephant disease or infection rates. Pregnant cows and calves should be identified and monitored on a quarterly or biannual basis and the owner should be contacted regularly by telephone to determine the elephants' health status.
Table 3. Elephas maximus. Growth rates and extinction risk of 7 population viability scenarios for Lao captive elephants. Time until first extinction is given as mean $\pm \mathrm{SD}$; scenarios are described in Table 1

\begin{tabular}{|ccccc|}
\hline $\begin{array}{c}\text { Scenario } \\
\text { Growth } \\
\text { rate }\end{array}$ & $\begin{array}{c}\text { Probability of } \\
\text { extinction (\%) }\end{array}$ & $\begin{array}{c}\text { Time until first } \\
\text { extinction }\end{array}$ & $\begin{array}{c}\text { Years until } \\
\text { extinction }\end{array}$ \\
\hline 1 & -0.099 & 100 & $41.06 \pm 25.86$ & 112 \\
2 & -0.081 & 100 & $45.42 \pm 27.77$ & 136 \\
3 & -0.064 & 100 & $53.05 \pm 32.92$ & 183 \\
4 & -0.064 & 100 & $58.85 \pm 38.52$ & 154 \\
5 & -0.047 & 100 & $70.74 \pm 49.60$ & 219 \\
6 & -0.064 & 100 & $65.26 \pm 41.36$ & 180 \\
7 & -0.047 & 100 & $74.36 \pm 52.35$ & 220 \\
\hline
\end{tabular}

\section{Increasing fecundity rates}

The small number of reproductively viable females inhibits significant population growth, although an increase in fecundity does assist population persistence. The tourism and export industries are driving demand for calves, with purchase prices reaching $>\$ 30000$ US (Suter et al. 2013). The high price for calves may now be a very good financial incentive for mahouts to undertake breeding programs,

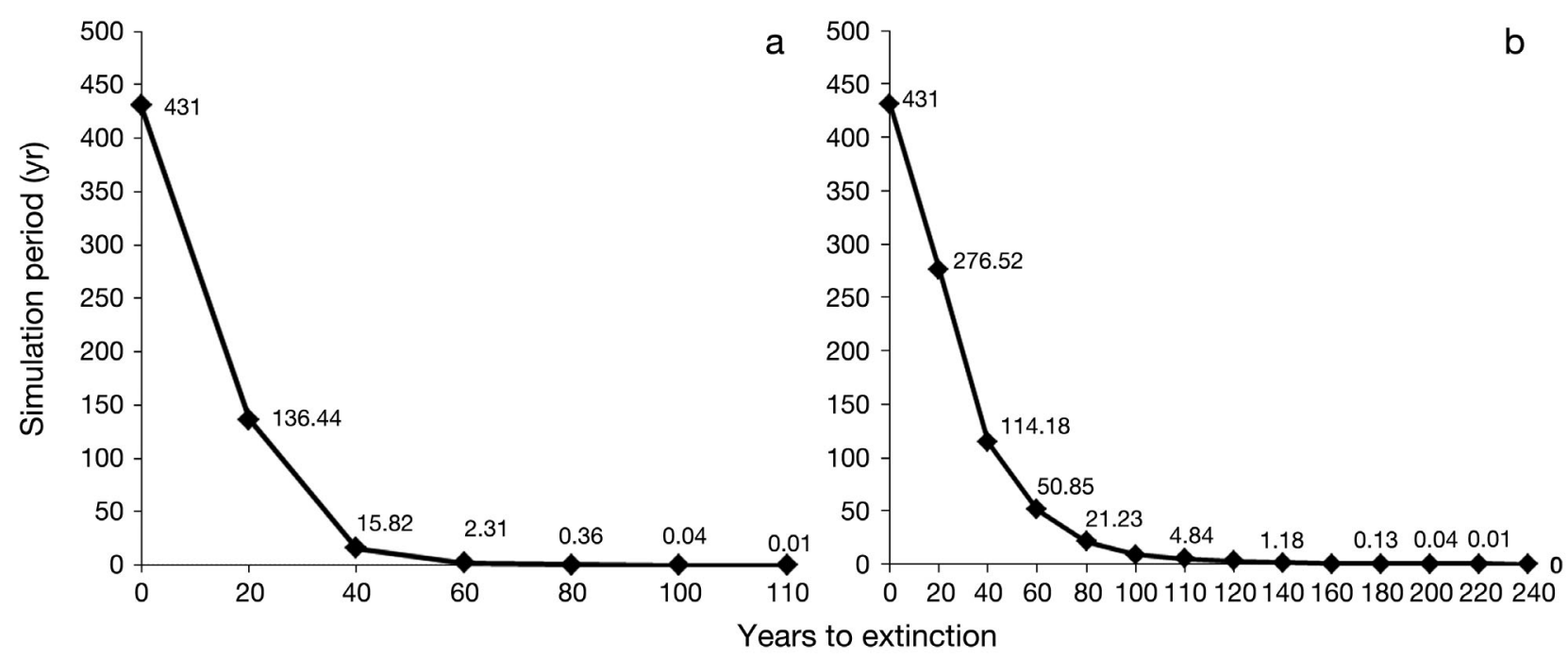

Fig. 2. Elephas maximus. VORTEX population trajectories of the captive Lao population, in a 500 yr simulation time period. (a) The baseline scenario indicates extinction in $112 \mathrm{yr}$, whereas (b) the Management Scenario 7 indicates extinction in $220 \mathrm{yr}$ 
and more mahouts should be encouraged to participate. Conservation management should identify and target the owners of cows $30 \mathrm{yr}$ and under for breeding incentives. There have previously been arrangements between non-governmental organizations and mahouts to enable their cows to breed, demonstrating that Lao mahouts are willing to stop work for conservation measures if economic losses are not incurred (Suter 2011). Training in estrus detection is also an important skill for mahouts to develop. However, it must be ensured that calves born as a result of breeding programmes are kept in the country and not rented or sold to other nations by the Government of Laos.

\section{Population supplementation}

Our analysis indicates that calf supplementing provides the population with greater persistence than increasing female reproduction rates or reducing mortality. We propose a transparent rental agreement from another range nation of Elephas maximus indicus as a method to safeguard the Lao elephant population. Rental agreements regarding Appendix 1 species are permitted under CITES regulations, to which Laos, Thailand and India are all signatories (Choudhury et al. 2008). Additions of new elephants may be expensive, but could prevent extinction of the Lao captive elephant population. An International Non-Government Organisation could organize the rental agreements and be responsible for management of the elephants and a breeding program while they are in Laos. While supplementation would be an arduous task, it may be unnecessary if all calves born into captivity are accounted for and used for in situ reproductive purposes rather than exported for diplomatic purposes. If exportation continues, a transparent rental agreement with another range nation of E. m. indicus may be necessary to avoid regional extinction.

\section{Management implications}

The analyses reported here used the best available estimates of population parameters for captive elephants in Lao PDR. These findings suggest that, while still important for industries and communities, the Lao captive elephant population requires greater management for population persistence; therefore, it should not be considered as a separate management unit. Rather, management of the captive Asian ele- phant population should be conducted across national boundaries in order to establish a greater chance of preventing regional extinction. This management may take the form of transfers of young to supplement local populations and prevent the genetic problems associated with small population sizes. It may also be feasible to set targets for the growth of regional populations and to provide incentives or rewards for meeting those targets. While discussion continues concerning greater cooperation between range nations, in reality, actions and funding toward this goal have so far been insignificant (Lair 2002, Dublin et al. 2006). Funding for Lao captive elephant management is urgently needed if this regionally significant population is to persist.

Acknowledgements. The authors appreciate the assistance given by the Department of Livestock and Fisheries' director Dr. Bounkouang and the National Animal Health Center's director Dr. B. Douangneun. We also thank the staff at ElefantAsia, specifically S. Duffillot, T. Douangdy and V. Chanthavong for database compilation and the intrepid task of captive elephant microchipping. Veterinarians supervising the Mobile Veterinary Unit field missions included Dr. B. Bouchard, Dr. J. Lassausaie and Dr. A. Bret. ElefantAsia appreciates the financial support received from Critical Ecosystems Partnership Fund to microchip and to create the Lao national elephant registration database.

\section{LITERATURE CITED}

Ahlering M, Hedges S, Johnson A, Tyson M, Schuttler S, Eggert L (2011) Genetic diversity, social structure, and conservation value of the elephants of the Nakai Plateau, Lao PDR, based on non-invasive sampling. Conserv Genet 12:413-422

Akçakaya H, Sjögren-Gulve P (2000) Population viability analyses in conservation planning; an overview. Ecol Bull 48:9-21

> Armbruster P, Fernando P, Lande R (1999) Time frames for population viability analysis of species with long generations: an example with Asian elephants. Anim Conserv 2: 69-73

Bandara R, Tisdell C (2004) The net benefit of saving the Asian elephant: a policy and contingent valuation study. Ecol Econ 48:93-107

Beissinger M, Westphal MI (1998) On the use of demographic models of population viability in endangered species management. J Wildl Manag 62:821-841

Choudhury A, Lahiri Choudhury DK, Desai A, Duckworth A and others (2008) Elephas maximus. www.iucnredlist .org/apps/redlist/details/7140/0 (accessed 19 April 2011)

Clubb R, Rowcliffe M, Lee P, Mar K, Moss C, Mason G (2009) Fecundity and population viability in female zoo elephants: problems and possible solutions. Anim Welf 18:237-247

Dublin H, Desai AA, Hedges S, Vié JC, Bambaradeniya C, Lopez A (2006) Asian Elephant Range States Meeting, 24-26 January 2006, Juala Lumpur, Malaysia Report. In: 
IUCN Species Survival Commission (ed) Elephant Range States Meeting, Kuala Lumpur. www.cites.org

Duffy R, Moore L (2011) Global regulations and local practices: the politics and governance of animal welfare in elephant tourism. J Sustainable Tourism 19:589-604

ElefantAsia (2007) Report: condition of Lao domesticated elephants 2007. ElefantAsia, Vientiane

ElefantAsia (2012) ElefantAsia (V1-7) database. ElefantAsia, Vientiane

Faust LJ, Thompson SD, Earnhardt JM (2006) Is reversing the decline of Asian elephants in North American zoos possible? An individual-based modeling approach. Zoo Biol 25:201-218

Harrison D, Schipani S (2009) Tourism in the Lao People's Democratic Republic. In: Hitchcock M, King VT, Parnwell M (eds) Tourism in Southeast Asia: challenges and new directions. Nordic Institute of Asian Studies, Copenhagen, p 172-180

Hedges S (2006) Conservation. In: Fowler MT, Mikota S (eds) Biology, medicine, and surgery of elephants. Blackwell Publishing Professional, Ames, IA, p 475-488

Hedges S, Tyson M, Sitompul A, Kinnaird M, Gunaryadi D (2005) Distribution, status, and conservation needs of Asian elephants (Elephas maximus) in Lampung Province, Sumatra, Indonesia. Biol Conserv 124:35-48

Khounboline K (2011) Current status of Asian elephants in Lao PDR. Gajah 35:62-66

Kontogeorgopoulos N (2009) Wildlife tourism in semicaptive settings: a case study of elephant camps in northern Thailand. Curr Issues Tourism 12:429-449

Labatut F, Suter I (2010) The veterinary care of domesticated elephants in Laos by a mobile veterinary unit. Gajah 32: 21-26

Lacy R (1993) VORTEX: a computer simulation model for population viability analysis. Wildl Res 20:45-65

Lacy RC (2000) Considering threats to the viability of small populations using individual-based models. Ecol Bull 48: 39-51

Lair R (1997) Gone astray: the care and management of the Asian elephant in domesticity. Food and Agriculture Organization of the United Nations, Bangkok

Lair R (2002) A regional overview of the need for registration of domesticated Asian elephants. In: Baker I, Kashio M (eds) Giants on our hands: Proc Int Workshop on the domesticated Asian elephant, 5-10 February 2001, Bangkok. UN FAO Regional Office for Asia and the Pacific, Bangkok, p 8-13

Leimgruber P, Senior B, Uga, Aung M and others (2008) Modeling population viability of captive elephants in Myanmar (Burma): implications for wild populations. Anim Conserv 11:198-205

Mar K (2002) The studbook of timber elephants of Myanmar

Editorial responsibility: Nils Bunnefeld,

Stirling, UK with special reference to survivorship analysis. In: Baker I, Kashio M (eds) Giants on our hands: Proc Int Workshop on the domesticated Asian elephant, 5-10 February 2001, Bangkok. UN FAO Regional Office for Asia and the Pacific, Bangkok, p 195-211

Miller P, Lacy R (2005) VORTEX: a stochastic simulation of the extinction process, Version 9.50's user's manual. Conservation Breeding Specialist Group (SSC/IUCN), Apple Valley, MN

Ministry of Agriculture and Forestry (2009) National Elephant Management Action Plan: Lao PDR. Vientiane, Lao PDR

Myroniuk P (2004) Population viability analysis of captive Asian elephants in Australia: a conservation assessment. Humane Society International Australia. www.hsi.org.au/ editor/assets/legal/PVA_Report.pdf (accessed 5 December 2011)

Norachack B (2002) The care and management of domesticated Asian elephants in Lao PDR. In: Baker I, Kashio M (eds) Giants on our hands: Proc Int Workshop on the domesticated Asian elephant, 5-10 February 2001, Bangkok. UN FAO Regional Office for Asia and the Pacific, Bangkok, p 172-180

Phakdisoth L, Kim D (2007) The determinants of inbound tourism in Laos. ASEAN Econ Bull 24:225-237

Saragusty J, Hermes R, Göritz F, Schmitt DL, Hildebrandt TB (2009) Skewed birth sex ratio and premature mortality in elephants. Anim Reprod Sci 115:247-254

Sukumar R (2003) The living elephants: evolutionary ecology, behavior, and conservation. Oxford University Press, New York, NY

Sukumar R (2006) A brief review of the status, distribution and biology of wild Asian elephants Elephas maximus. Int Zoo Yearb 40:1-8

Sukumar R, Santiapillai C (1993) Asian elephant in Sumatra population and habitat viability analysis. Gajah 11: 59-63

Suter I (2011) Luxembourg Government assists with Lao elephant reproduction. Available at: www.elefantasia. org/spip.php?article160\&lang=en (accessed 5 December 2013)

Suter IC (2012) Really Laos, you shouldn't have: giving elephants to Japan is a bad idea. http://theconversation. edu.au/really-laos-you-shouldnt-have-giving-elephantsto-japan-is-a-bad-idea-9778 (accessed 13 September 2013)

Suter IC, Hockings M, Baxter G (2013) Changes in elephant ownership and employment in the Lao PDR: implications for the elephant-based logging and tourism industries. Hum Dimens Wildl 18:279-291

Xaymountry B, Maurer G (2011) Note on domesticated elephant management in Lao PDR. ElefantAsia, Vientiane

Submitted: September 13, 2013; Accepted: January 7, 2014

Proofs received from author(s): March 7, 2014 